\section{The ATS/ERS consensus on clinical pulmonary function testing}

Recently, the need for more uniform pul-

monary function testing across the world has progressively increased. This prompted the American Thoracic Society (ATS) and the European Respiratory Society (ERS) to appoint a joint Task Force to provide new combined standards. The Task Force consisted of 19 scientists with recognised expertise in pulmonary function testing, who met many times to produce their new standards, which, in July, started to appear as a series in five consecutive issues of the European Respiratory Journal [1-5]. The five manuscripts deal with the most relevant aspects of pulmonary function testing in hospital-based laboratories, including the following:

$>$ General considerations for lung function testing

$>$ Standardisation of spirometry

$>$ Standardisation of measurement of lung volumes

> Standardisation of the single breath determination of carbon monoxide uptake in the lung

$>$ Interpretative strategies for lung function tests

The spirometry document is an update of all the important elements of this test, from instrument to procedure quality control, and combines the previous guidelines published separately by the ERS and ATS. Metrology definitions have been introduced according to the International Organization for Standardization and some old ones have been abandoned. Thus, different definitions for repeatability and reproducibility are now given, while the concept of precision is no longer considered. A practical consequence is that there is no longer a distinction between diagnostic and monitoring devices, i.e. the same degree of accuracy is required for all devices regardless of their intended use.

The lung volume document is based on a document previously published by the ERS and an unpublished document produced after an international workshop that was funded by the

\section{Brusasco \\ G. Viegi $^{2}$}

${ }^{1}$ Internal Medicine, University of Genoa, Genova, and ${ }^{2}$ Istituto di Fisiologia Clinica CNR, Pisa, Italy.

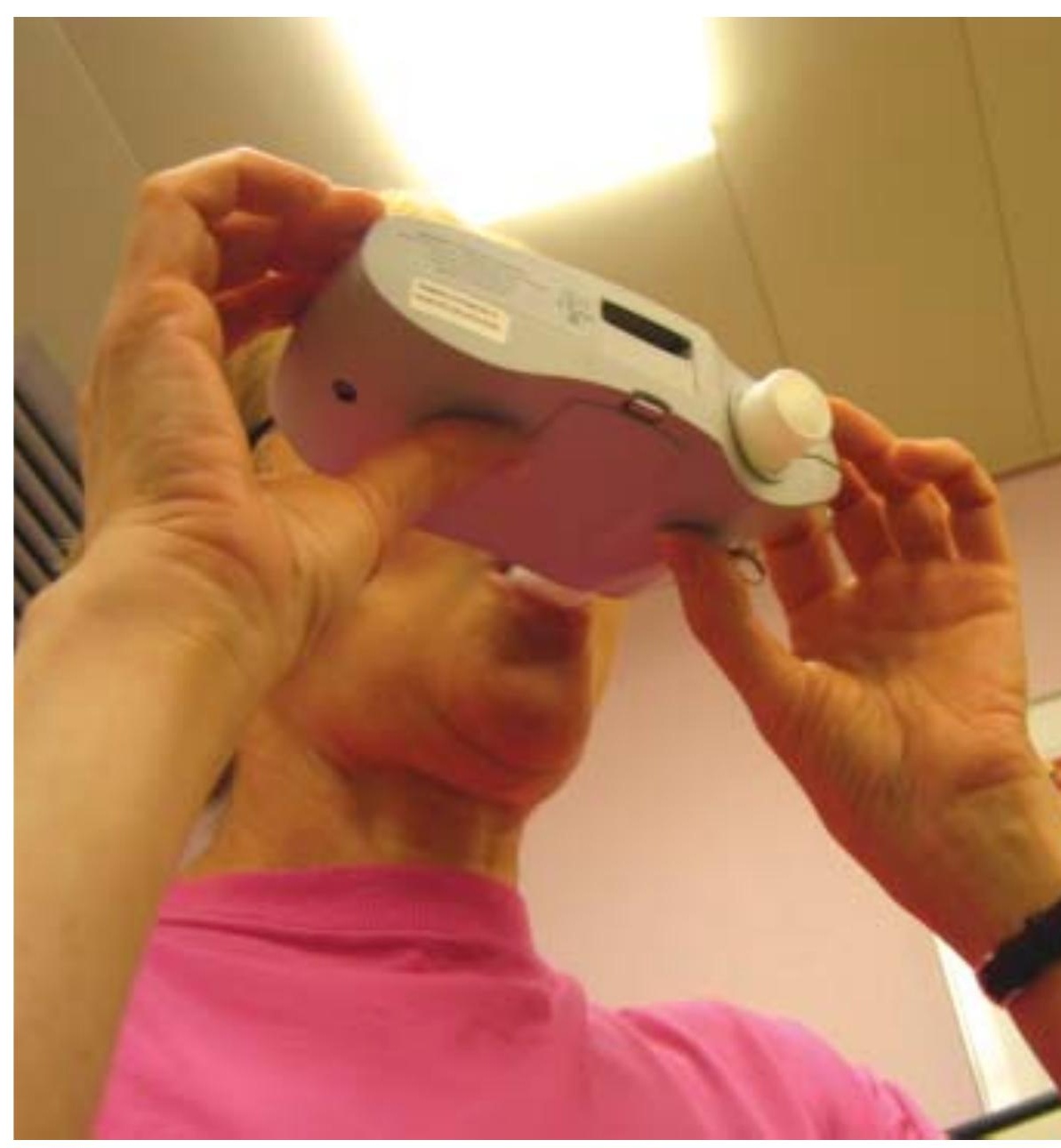




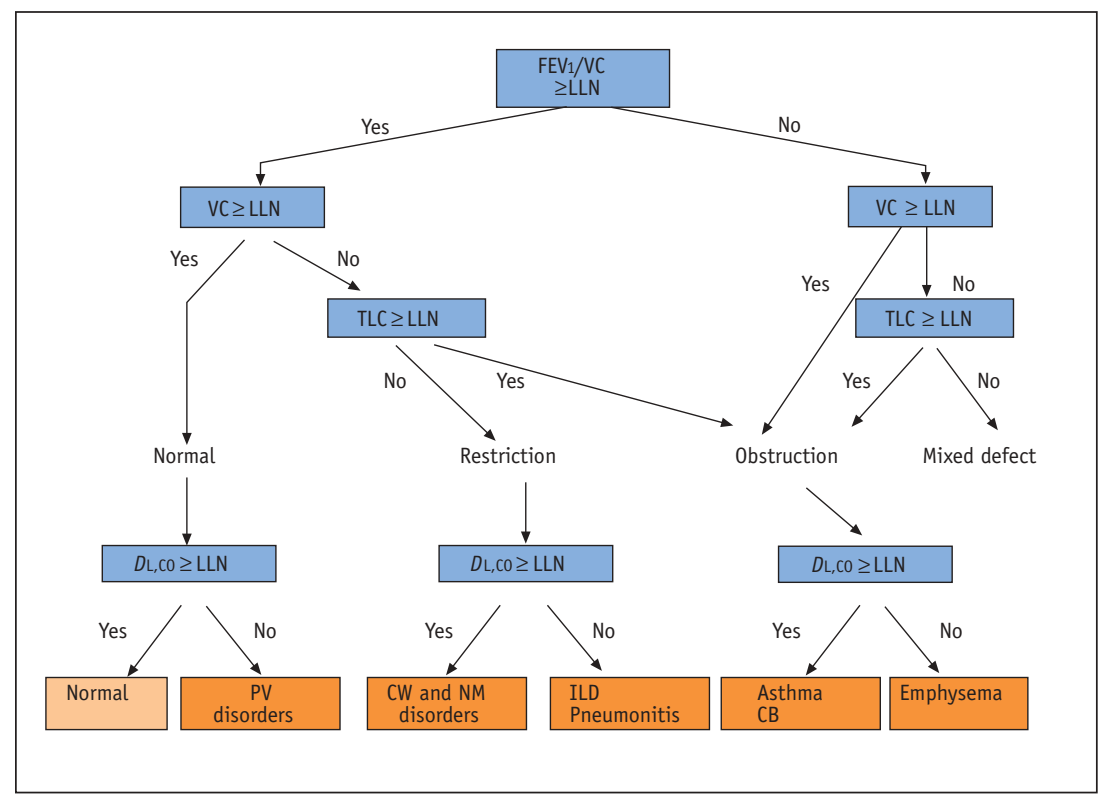

Figure 1

A simplified algorithm that may be used to assess lung function in clinical practice. VC: vital capacity; LLN: lower limits of normal; TLC: total lung capacity; $D L, C O$ : diffusing capacity for carbon monoxide; PV: pulmonary vascular; CW and NM: chest wall and neuromuscular; ILD: interstitial lung disease; $C B$ : chronic bronchitis. Modified with permission from [5].

Please see original paper for full descriptions and discussion.
National Heart Lung and Blood Institute(NHLBI). Here, all relevant technical aspects and limitations of the various methods currently available for lung volume measurements are analysed in detail.

The diffusing capacity $(D \mathrm{~L}, \mathrm{CO})$ document combines former guidelines published separately by the ERS and ATS. The areas of concern were primarily related to adjustments of $D \mathrm{~L}, \mathrm{CO}$ for lung volume (i.e. using $D \mathrm{~L}, \mathrm{co} /$ alveolar volume $\left(V_{\mathrm{A}}\right)$ ), and the question of how to interpret unadjusted and adjusted values if the decision was to adjust for lung volume. It was agreed by all that the simple $D \mathrm{~L}, \mathrm{CO} / V_{\mathrm{A}}$ does not necessarily "correct" for a reduced $D L, C O$ in the setting of a comparably reduced $V_{A}$, pointing to the need for more research into the clinical utility of $D \mathrm{~L}, \mathrm{CO} / V_{\mathrm{A}}$. There was also a significant discussion concerning adjustments for haemoglobin and carboxyhaemoglobin concentrations. It was agreed to adjust for these to the predicted rather than the measured values. In respect to terminology, although the term "transfer factor" is more correct from a scientific standpoint, perhaps it was the long history and common usage of $D \mathrm{~L}, \mathrm{CO}$ that gave it the edge. Since most intra-session variability is technical rather than physiological, it was also thought reasonable to recommend reporting the mean of two acceptable tests that meet the repeatability requirement of either being within $3 \mathrm{~mL} \mathrm{CO} \cdot \mathrm{min}^{-1} \cdot \mathrm{mmHg}^{-1}$ (STPD) (or $1 \mathrm{mmol} \cdot \mathrm{min}^{-1} \cdot \mathrm{kPa}^{-1}$ ) of each other or within 10\% of the highest value. According to the literature, $>95 \%$ of patients could meet this criteria. Research is needed to determine the actual number of tests required to provide a reasonable estimate of an average $D \mathrm{~L}, \mathrm{CO}$ value for a given person. More than five tests are not recommended at the present time.

The interpretative strategies document represents the most innovative part produced by the Task Force. Although it generated rather strong controversy in some areas, it emphasises at least two crucial points that those working in a pulmonary function laboratory must consider before deciding which test to do in which patient and how to make conclusions about the presence and type of lung function abnormality. On one hand, it is important to select appropriate reference values and lower limits of the normal range, in addition to updating or even generating new reference equations for more race/ethnicity groups. On the other hand, a sequential approach was proposed for the use of different lung function tests in good clinical practice (figure 1). Although this is not mandatory for everybody and may only be used in large, hospital-based laboratories, this algorithm represents a state-of-the-art procedure to reach the right diagnosis in the vast majority of patients, and also outlines the limitations that must be kept in mind when interpreting data obtained by simple spirometry. In addition, the assessment of reversibility of airway obstruction is covered in more detail than in previous documents, emphasising that changes in lung volumes may be more likely to occur than improvements in forced expiratory volume in one second ( $\left.\mathrm{FEV}_{1}\right)$ in many chronic obstructive pulmonary disease patients.

We believe that the considerable effort made by this ATS/ERS Task Force has produced a good, albeit not perfect, set of documents that should be used as a guide for good clinical practice and hopefully adopted by other scientific societies until changes are made based on new scientific evidence.

\section{References}

1. Miller MR, Crapo R, Hankinson J, et al. General considerations for lung function testing. Eur Respir J 2005; 26: 153-161.

2. Miller MR, Hankinson J, Brusasco V, et al. Standardisation of spirometry. Eur Respir J 2005; 26: 319-338.

3. Wanger J, Clausen JL, Coates A, et al. Standardisation of the measurement of lung volumes. Eur Respir J 2005; 26: 512-523.

4. MacIntyre N, Crapo R, Viegi $G$, et al. Standardisation of the single breath determination of carbon monoxide uptake in the lung. Eur Respir J 2005; 26: (In press).

5. Pellegrino R, Viegi G, Enright $P$, et al. Interpretative strategies for lung function tests. Eur Respir J 2005; 26: (In press). 